\title{
Investigating the effect of teacher mediation on student expressed reasoning
}

\begin{abstract}
Patricia Moreira ${ }^{*}$, Ainoa Marzabal ${ }^{a}$, and Vicente Talanquer ${ }^{b}$
Understanding how chemistry teachers' interventions shape the reasoning that students express after a lesson is critical to support prospective and in-service teachers as they work with students' ideas in the classroom. In this qualitative research study, we analysed changes in the reasoning expressed by $10^{\text {th }}$ grade students in a Chilean school in their written explanations about freezing point depression before and after a lesson on the topic. We also investigated how the teacher's interventions shaped the type of reasoning expressed by participating students. Our findings revealed significant shifts in the types of explanations generated after the lesson. A significant number of students transitioned from relational to simple causal reasoning in their pre- and post-lesson explanations. After de lesson most of the explanations were based on the activities of one or more of the system's entities. Analysis of teacher-student interactions during the observed lesson suggests that the teacher's mediation played a central role in the shift towards simple causal reasoning with centralized causality that was observed. The teacher in our study was more skilled at eliciting students' ideas than at helping students develop them with proper scaffolding. Thus, the observed classroom talk could not be considered as accountable talk, as most of the key ideas were introduced, selected, or reshaped by the teacher.
\end{abstract}

\section{Introduction}

Constructing explanations of every day phenomena requires the development of complex ways of reasoning (Grotzer, 2012; Grotzer, 2003). These types of reasoning demand identifying diverse and interacting causal relationships using appropriate scientific ideas to build explanations (Izquierdo \& Aliberas, 2004). Engaging students in the construction and evaluation of explanations and arguments helps them better understand targeted concepts and develop their ability to use science practices in problem-solving and decision-making (McNeill \& Krajcik, 2012). This work may be challenging, however, as student reasoning often relies on intuitive assumptions and heuristic rules that help reduce cognitive demand (Maeyer \& Talanquer, 2010; Talanquer, 2014).

Although different types of explanations may be built to explain a phenomenon, it is common in many scientific fields, including chemistry, to build mechanistic accounts (Russ, Scherr, Hammer, \& Mikeska, 2008). Mechanistic explanations are based on the characterization of the properties, interactions, activities, and spatio-temporal organization of core model components of a system assumed to be responsible

\footnotetext{
a. Facultad de Educación, Pontificia Universidad Católica de Chile, Santiago, Chile. E-mail:pmmoreira@uc.cl

b. Department of Chemistry and Biochemistry, University of Arizona. Tucson, Arizona 85721, USA. E-mail: vicente@u.arizona.edu
}

for the phenomenon under analysis (Russ et al., 2008). Although students at all educational levels have the ability to build mechanistic accounts of natural phenomena (Becker, Noyes, \& Cooper, 2016; Moreira, Marzabal, \& Talanquer, 2019; Russ, Coffey, Hammer, \& Hutchison, 2009), their reasoning needs to be scaffolded and opportunities need to be created to make student thinking visible and provide formative feedback (Aydeniz \& Dogan, 2016; Russ et al., 2008).

In a recent study, we investigated the different types of reasoning initially expressed by $10^{\text {th }}$ grade students in a Chilean school when asked to explain the phenomenon of freezing point depression in a mixture of water and alcohol (Moreira et al., 2019). Our study revealed that a majority of the participants built relational or simple causal explanations of this phenomenon. There were, however, students who generated mechanistic explanations involving the spatio-temporal organization of entities in the system. Although these explanations were non-canonical, they revealed students' ability to engage in mechanistic reasoning.

In this contribution, we analyse the types of explanations generated by the same group of students after a lesson designed by their teacher to help them understand freezing point depression. Our interest is twofold. On the one hand, we seek to characterize changes in student reasoning as a result of a teaching intervention. On the other hand, we want to analyse how a teacher's decisions and actions influenced student reasoning as expressed in a post-lesson task. The secondary 
school teacher who participated in our study had been trained in the use of high-leverage teaching practices in the classroom (Grossman, Hammerness, \& McDonald, 2009), but had only two years of teaching experience. This teacher designed and implemented the observed lesson on her own, and was not aware of the specific goals of our research study. Our central goal in this part of the investigation is to provide insights into how a teachers' mediation influences expressed student reasoning. This type of analysis is needed to better support the work of teachers as they engage in the implementation of evidence-based teaching practices.

\section{Teachers' mediation in science classrooms}

The significant influence that teachers have on the learning process has been recognized for many years. Several studies have revealed critical characteristics of knowledge for teaching (Alvarado, Cañada, Garritz, \& Mellado, 2015; Garriz, Nieto, Padilla, Reyes-cárdenas, \& Velasco, 2008; Magnusson, Krajcik, \& Borko, 1999; Shulman, 1987), as well as key teaching competencies and core practices (Aydeniz \& Dogan, 2016; Bell \& Cowie, 2001; Grossman et al., 2009; McDonald et al., 2014; Thompson, Windschitl, \& Braaten, 2013; Windschitl, Thompson, Braaten, \& Stroupe, 2012) that best foster meaningful learning. Research on knowledge for teaching using a pedagogical content knowledge (PCK) framework (Shulman, 1987) has helped characterize the types of specialized knowledge that effective teachers have, such as knowledge of curricular goals, discipline-specific instructional strategies, and students' difficulties in learning core concepts and ideas (Magnusson et al., 1999). This knowledge allows teachers to elicit and identify students' initial ideas, productively interpret student thinking, and select appropriate tasks to advance student understanding (Garriz et al., 2008; Talanquer, 2004).

Some authors have suggested that what teachers pay attention to has a great influence on the decisions they make and the actions they implement in the classroom (Levin, Hammer and Coffey, 2009; Russ, 2018; van Es \& Sherin, 2002). Russ (2018) has highlighted different approaches in the characterization of teacher attention to student thinking that consider the object of attention, the level of attention, the knowledge used in teacher attention, and the discursive practices employed in listening to students' ideas. This author has suggested that although these different approaches point to critical elements in a teacher's attention, it is also important to consider the messages that teachers implicitly send to students by what they pay attention to (i.e., what knowledge elements, ways of thinking, or practices they highlight).

The discourse moves that teachers use in working with student thinking seem to have a major influence on the level of reasoning manifested in a classroom (Michaels \& O'Connor, 2015). Specific types of talk have been recognized as better at fostering construction of knowledge and scientific reasoning. For example, "accountable talk" (Wolf, Crosson, \& Resnick, 2006) or "exploratory talk" (Mercer, 2004) engage students in sharing ideas based on explicit facts, making coherent relations, and generating reasonable conclusions (Michaels, O' Connor, \& Resnick, 2008).

Mortimer and Scott (2003) have proposed five critical dimensions in the analysis of the interactions and meanings constructed in the classroom: communicative approach, teacher's intentions, content, interaction patterns, and teacher interventions. A teacher's communicative approach is characterized on a continuum that stretches from an interactive/dialogic approach to a non-interactive/authoritative approach. When teachers adopt a dialogic approach, they explore students' ideas and create opportunities for students to construct their understanding through dialogue. When teachers adopt an authoritative approach, they present a specific point of view that students are expected to understand and embrace.

The interaction patterns in which teachers engage in a classroom and the pedagogical interventions that they implement are guided by their pedagogical intentions (Mortimer \& Scott, 2002). Through their use of spoken and written language, teachers work as mediators during the learning process creating or constraining opportunities for the development of student reasoning (Mercer, 2004; Michaels et al., 2008). Studies in this field have revealed the central role that classroom dialogue plays in shaping the learning that takes place (Dawes, 2004; Maine \& Hofmann, 2016; Mercer \& Howe, 2012; Michaels \& O'Connor, 2015; Rojas-Drummond, Torreblanca, Pedraza, Vélez, \& Guzmán, 2013). For example teachers that elicit students' ideas, engage with these ideas in meaningful ways through conversation, and adapt instruction in response to these ideas are more likely to foster the development of meaningful understandings (Thompson et al., 2013; Windschitl et al., 2012).

A teacher's pedagogical interventions may be varied and guided by diverse intentions, such as exploring students' ideas, sharing meanings, highlighting key ideas, monitoring comprehension, or gathering and anticipating meanings (Mortimer \& Scott, 2002). These interventions send messages to students about the types of understandings, skills, ways of reasoning, and practices that are valued (Russ, 2018). A core goal of the present study was to investigate how a teacher's approach and interventions shaped the type of reasoning that students expressed after a chemistry lesson. The results of our analysis provide insights into the productive and constraining effects that teacher mediation has in the development of different forms of reasoning in the classroom.

\section{Research Questions}

This study focused on a) the analysis of students' written explanations after a chemistry lesson on freezing point depression seeking to characterise change in underlying ways of reasoning, and b) the analysis of how a teacher's decisions and actions in the classroom shaped students' expressed reasoning. In particular, the following research questions guided our study:

- How does student reasoning change as a result of a teaching intervention?

- How do a teacher's decisions and actions influence the types of reasoning that students express after a lesson? 


\section{Methodology}

\section{Context and Participants}

This research was carried out in a Chilean private-subsidized secondary school. Data was collected from two $10^{\text {th }}$ grade chemistry classes taught by the same teacher with a total of 78 students (39 Female; 39 Male). The average student age was 15 years old. The participating teacher had been involved in training and professional development programs that focused on the implementation of highleverage teaching practices in the classroom (Grossman et al., 2009). Some of these practices included: (1) Explaining core content, (2) Eliciting and fostering student thinking, (3) Identifying common patterns in student thinking, and (4) Developing appropriate pedagogical responses. Although the teacher had only two years of teaching experience, she was already involved in mentoring preservice teachers. Data were collected as part of a lesson on colligative properties, in particular freezing point depression. The objective of this lesson was to explain the relationship between freezing temperature and solution concentration. Proper consent was obtained from all participants in the study.

\section{Research Instrument}

The research instrument used to explore student reasoning was the same described in a previous study (Moreira et al., 2019). The probe described a hypothetical scenario and asked students to build a written explanation for why alcohol can be used as antifreezer in cars. The probe also asked students to create a drawing to support their explanation. The instrument was used to probe student reasoning before and after the lesson on freezing point depression designed by the participating teacher.

\section{Data Collection}

Data was collected from the two $10^{\text {th }}$ grade chemistry classes taught by the participating teacher. Both classes were videorecorded and student written work associated with the research probe was collected. The teacher planned and implemented the observed lesson on her own, without any researcher intervention. The only request was for her to apply the research instrument at the beginning and end of the lesson. The lesson sequence is summarized in figure 1. The initial and final 10 minutes of the class were used for the students to individually complete the research instrument. The remaining 25 minutes were dedicated to the lesson. During this time, the teacher first started a conversation about the freezing process of pure substances using water as an example. Then, she engaged students in thinking about what may happen when a solute like salt is added to water. Different resources were used to support the lesson, such as images and video (Zaidan \& Morton, 2014). The teacher interacted with students on a regular basis by asking different questions and reacting to students' responses. The teacher repeated the same sequence of events in the two observed classes. At the end of these classes, a total of 148 written explanations to the research probe were collected ( 74 initial explanations and 74 final explanations). Four students in the sample did not answer either the initial or final probes and their responses were not analysed.

\section{Data analysis}

Written explanations and classroom interactions were analysed using a constant comparison method (Creswell, 2013; Miles \& Huberman, 1994). To answer the research question, the analysis was conducted at two different levels. First, we characterised student reasoning in post-lesson written explanations as well as the reasoning expressed by the teacher during the lesson. Second, we analysed how different reasoning components manifested during the lesson in relation to the teacher's interventions. In both cases, the analysis was carried out by the first two authors of this study on a representative data sample and individual codes were then compared and discussed. Disagreements were resolved through various rounds of discussion. The final schemes were then applied by the first author of this paper to analyse the entire data set.

Our analysis of reasoning in written work and in the classroom relied on the framework developed in our previous work (Moreira et al., 2019). This framework can be used to characterize different elements in an explanation:

a) Entities (E): Material components of the system. They may include macroscopic (e.g., substances) or submicroscopic (e.g., particles) components.

b) Properties ( $P$ ): Characteristics of the entities that are relevant in building the explanation. They may be general or specific. Some examples include freezing point and mass.

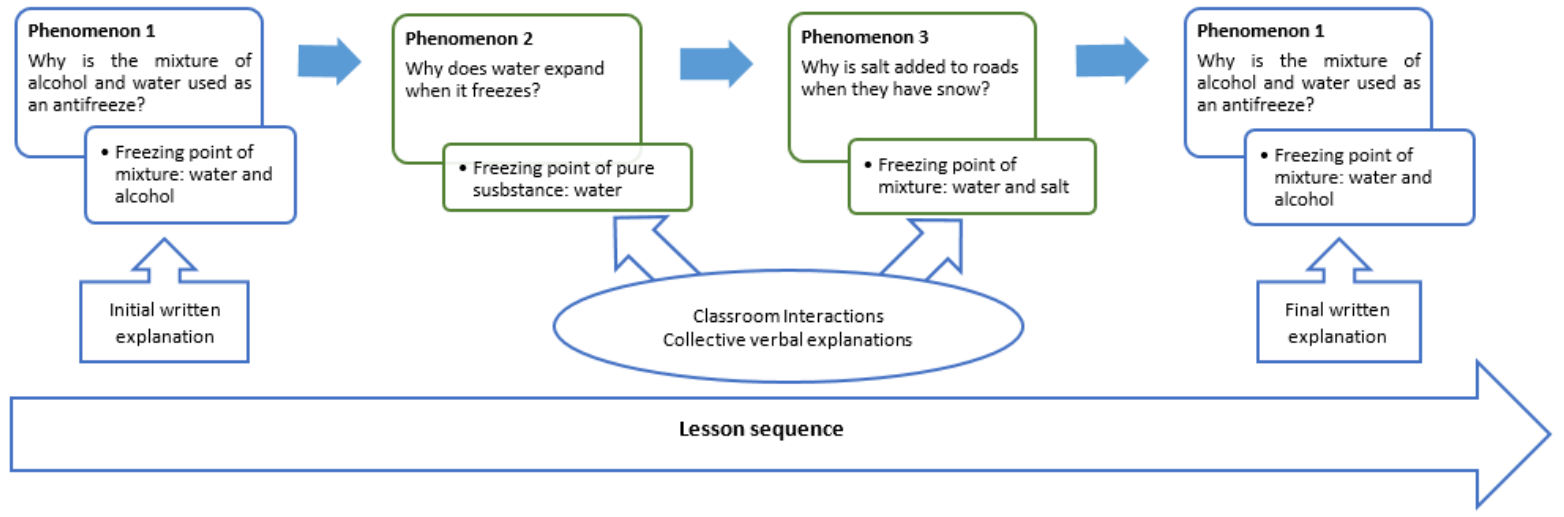

Fig. 1: Sequence of events for the lesson observed in both chemistry classes 
The analysis identifies the entity associated with the cited property and the type of property that is invoked.

c) Activities (A): Actions/interactions cited as causing changes to entities and/or to the whole system. These activities establish explicit cause-effect relationships. The analysis identified what entity is involved in the action or interaction, and, the type of activities (there may be more than one) invoked in the explanation.

d) Organization (O): This category refers to the spatialtemporal location of the entities during a determined activity and its causal connection to the properties or behaviour of the system.

e) Representations (R): This category refers to the extent to which the drawing provides additional insights into student reasoning. Drawings were used in our analysis to identify other explanatory components not present in the written explanations, such as entities or organization.

The types of elements manifested in each of the collected explanations, and the relationship between them, was made explicit using reasoning diagrams such as that in figure 2. In these diagrams, different coloured shapes are used to identify different types of reasoning elements, and blue arrows represent causal connections.

In the second part of our analysis, we applied the framework developed by Mortimer and Scott (2002) to characterise classroom talk. In particular, we used their characterization of teachers interventions to describe the teacher's decisions and actions when constructing explanations about freezing point depression in the classroom. Three of the categories of analysis involved exploring students' ideas and working with meanings. These categories were shaping meanings, selecting meanings, and marking key meanings. The other categories were: sharing meanings, when the teacher made meanings available to all students in the class; and monitoring student understanding, when the teacher verified what meanings students attribute in specific situations. Here we present specific descriptions of the teacher's actions associated with each category:

a) Shaping meanings: The teacher introduces a new term, paraphrases a student's response, or shows the difference between two meanings.

b) Selecting meanings: The teacher considers or ignores a student's response.

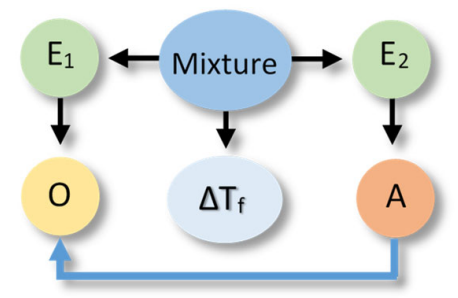

Fig. 2. Example of reasoning diagram. In this case, the explanation attributes the phenomenon of freezing point depression $\Delta T_{f}$ in a water (entity $E_{1}$ ) - alcohol (entity $E_{2}$ ) mixture to an activity $(A)$ of $E_{2}$ that affects the organization of $E_{1}$. c) Marking key meanings: The teacher repeats a statement; asks the students to repeat a statement; engages in an interrogation (I)- response (R) - evaluation (E) sequence with a student to confirm an idea; uses a particular tone of voice to highlight certain parts of a statement.

d) Sharing meanings: the teacher repeats the idea of a student to the whole class; asks a student to repeat a statement to the class; shares results of different groups with the class; asks students to organize ideas or experimental data to report to the entire class.

e) Monitoring student understanding: the teacher asks a student to explain better an idea; asks students to write their explanations; checks whether there is a consensus about certain meanings.

\section{Main Findings}

The results of our investigation have been organized into two sections. In the first section, we characterize changes in participating students' reasoning as expressed in their post-lesson written explanations. In the second section, we analyze the types of interventions made by the teacher during the lesson and how they shaped the type of reasoning that was promoted in the classroom. Qualitative data presented in the form of students' written explanations and excerpts from classroom interactions were translated from Spanish to English by a speaker fluent in both languages. Nuances in the original text and communications may have been lost in the translation. The orginal Spanish versions of the transcripts can be requested from the authors.

\section{Expressed reasoning in post-lesson student explanations}

In our original study (Moreira, Marzabal and Talanquer, 2019), the analysis of the pre-lesson explanations of freezing point depression led us to the identification of four major levels of sophistication in student reasoning: Level 1 (Descriptive) included responses that were descriptive in nature and limited to restating the phenomenon in different words. Explanations in Level 2 (Relational) relied on simple associations between properties of the main entities in the system. In Level 3 (Simple Causal), explanations were based on the activities of one or more of the system's entities, while explanations in Level 4 (Emerging Mechanistic) referred to an organisation of entities and activities in space and time to make sense of the phenomenon. These same levels were used to categorize post-lesson explanations and our results are summarized in Figure 3. This figure compares the percentage of explanations classified at each level in the pre-lesson and post-lesson stages in the two observed classes. Results for these two classes have been combined in this figure as students were exposed to essentially the same lesson.

Analysis of the data in figure 3 reveals a shift in the level of students' explanation towards Level 3 (simple causal). The percentage of students who expressed simple causal reasoning increased from $28 \%$ to $61 \%$, while that of students expressing other levels of reasoning decreased, from $15 \%$ to $9 \%$ for descriptive 


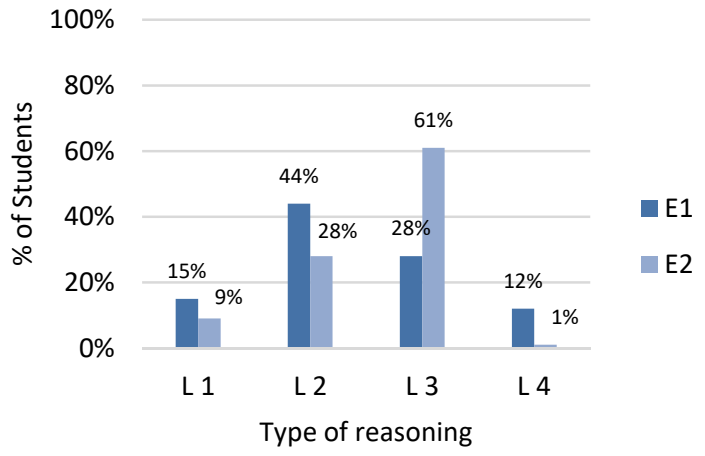

Fig. 3: Percentage of written explanations at each level of reasoning in the pre-lesson (E1) and post-lesson (E2) stages ( $N=74)$. L1-Descriptive, L2-Relational, L3 Simple Causal, L4- Emerging Mechanistic.

reasoning (L1), $44 \%$ to $28 \%$ for relational reasoning (L2), and from $12 \%$ to $1 \%$ for emerging mechanistic reasoning (L4).

We also analysed changes in individual explanations, focusing on the transitions in the level of reasoning before and after the lesson. For each level of reasoning we determined the percentage of students that, starting at each level, remained in the same level of reasoning or transitioned to a different level after the lesson. These results are summarized in table 1 . Of those students whose explanations showed descriptive reasoning (L1) before the lesson, the majority of them (60\%) remained at this level but some of them transitioned to relational (20\%) or simple causal reasoning $(20 \%)$ levels. Most of the students (59\%) who initially expressed relational reasoning (L2) transitioned to simple causal reasoning after the lesson, while a smaller percentage (35\%) remained at the same level. A few of these students transitioned to lower descriptive (3\%) or to higher emerging mechanistic (3\%) forms of reasoning. Most students who initially expressed simple causal reasoning (L3) remained at this level (67\%), while the rest of them transitioned to a lower level of reasoning (33\%). Finally, all students who showed mechanistic emergent reasoning (L4) before the lesson, transitioned to a lower simple causal reasoning level after the lesson.

Although a large percentage of students in our sample (46\%) expressed the same level of reasoning before and after the lesson, the content of their explanations changed. Table 2 shows a representative example in which a student's expressed reasoning remained at level 3, but the pre- and post-lesson explanations included different reasoning components. In this case, the initial

Table 1. Percentages of students that remained in the same level of reasoning (e.g., 1-1, 2-2) or transitioned to a different level (e.g., from Level 1 to 2 is showed as $1 \rightarrow 2$, from level 4 to $3,4 \rightarrow 3$ ) after the lesson.

\begin{tabular}{cccccccc}
\hline $\begin{array}{c}\text { Level } \\
1\end{array}$ & $\%$ & $\begin{array}{c}\text { Level } \\
2\end{array}$ & $\%$ & $\begin{array}{c}\text { Level } \\
3\end{array}$ & $\%$ & $\begin{array}{c}\text { Level } \\
4\end{array}$ & $\%$ \\
\hline $1-1$ & 60 & $2 \rightarrow 1$ & 3 & $3 \rightarrow 1$ & 0 & $4 \rightarrow 1$ & 0 \\
$1 \rightarrow 2$ & 20 & $2-2$ & 35 & $3 \rightarrow 2$ & 33 & $4 \rightarrow 2$ & 0 \\
$1 \rightarrow 3$ & 20 & $2 \rightarrow 3$ & 59 & $3-3$ & 67 & $4 \rightarrow 3$ & 100 \\
$1 \rightarrow 4$ & 0 & $2 \rightarrow 4$ & 3 & $3 \rightarrow 4$ & 0 & $4-4$ & 0 \\
\hline
\end{tabular}

explanation invoked a property of alcohol particles that caused them through an activity (hindering) to alter the properties of water. In the post-lesson explanation, references to properties disappeared and the phenomenon was explained by simply referring to the effect of an activity (hindering) of the alcohol particles on an activity (ordering) of water molecules.

The transition from levels of relational reasoning (L2) to simple causal (L3) was characterized by the introduction of "activity" components in students' expressed reasoning. In several of these cases, references to the properties of entities invoked in the initial explanations disappeared and causality was only linked to activities in which the entities engaged. This is illustrated in the example included in table 3 where the student initially referred to the purity of one substance and the freezing point of the other, but only invoked the hindering effect of the alcohol on the ordering of water particles in the post-lesson explanation.

Post-lesson explanations from students who transitioned down from an emerging mechanistic ( $L 4)$ to a simple causal (L3) level were also often characterized by references to an activity of an entity affecting an activity of the other entity, in contrast to references to the properties and organization of the components in the initial explanations. An example of this transition is illustrated in table 4.

Table 2: Example of no transition 3-3

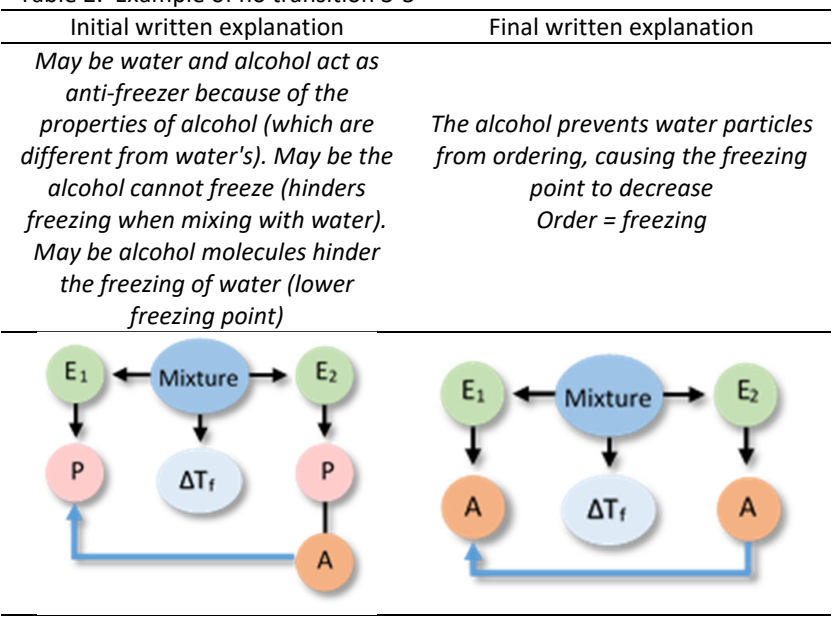

Table 3: Example of transition 2-3

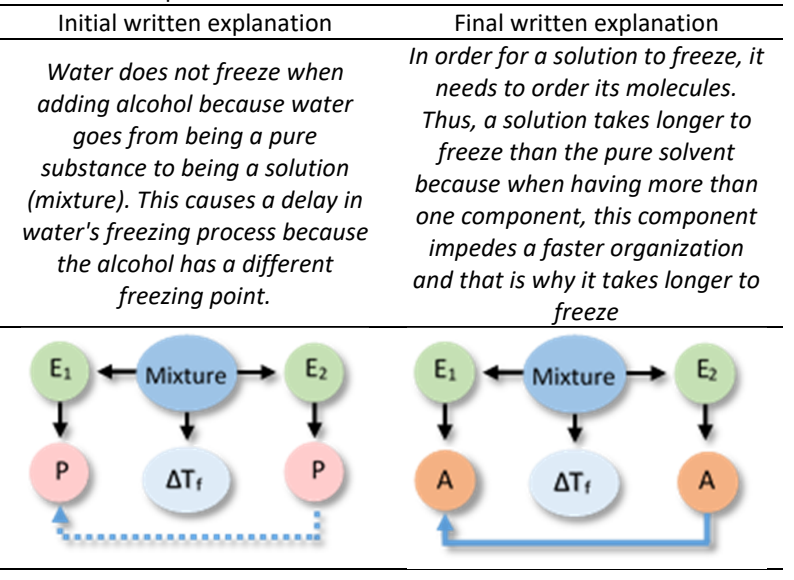


Table 4: Example of transition 4-3

Initial written explanation
$\begin{gathered}\text { I believe that the alcohol surrounds } \\ \text { the water molecules, preventing } \\ \text { that temperature from affecting the } \\ \text { water. I believe also that the alcohol } \\ \text { has a much higher freezing points } \\ \text { than water and because it surrounds } \\ \text { the water, it is difficult for the cold } \\ \text { of water to the freezing point. } \\ \text { ordered is the same as being } \\ \text { frozen. }\end{gathered}$

The analysis of the pre- and post-lesson explanations generated by all participants revealed a convergence towards a particular type of simple causal explanation in which the action of one of the entities (the alcohol) were responsible for the phenomenon (freezing point depression), without discussion of the properties of the entities involved or their spatio-temporal organization. There was also a reduction in the range of activities invoked by students in their explanations. Initial written explanations at levels 3 and 4 referred to activities such as hindering ordering (33\%), moving (21\%), reacting (21\%), and repelling (12\%). After instruction, however, the most common activities simultaneously invoked by students were "hindering" and "ordering" (98\%). This is seen in the examples included in tables 1 through 4.

\section{Agency in students' written explanations}

As part of our analysis, we also looked at changes in the nature of the agency invoked in students' written explanations. The types and frequency of agency identified in pre- and post-lesson explanations are summarized in table 5 . Here we can also see a convergent shift towards the alcohol acting as a barrier to or as a retardant of the freezing process. Specific examples of how students referred to different types of agency in their pre- and post-lesson explanations are presented in table 6 . In the case of student 47 , the alcohol passes from serving as a temperature insulator to acting as a barrier for the

Table 5: Agency in written explanations

\begin{tabular}{|c|c|c|c|}
\hline & Type of agency & $\begin{array}{l}\text { Pre-lesson } \\
\text { explanation }\end{array}$ & $\begin{array}{l}\text { Pot-lesson } \\
\text { explanation }\end{array}$ \\
\hline a) & $\begin{array}{l}\text { Alcohol as a barrier or } \\
\text { insulator }\end{array}$ & $20 \%$ & $53 \%$ \\
\hline b) & $\begin{array}{l}\text { Alcohol as a source of } \\
\text { energy }\end{array}$ & $13 \%$ & $0 \%$ \\
\hline c) & Alcohol as freezing retardant & $12 \%$ & $8 \%$ \\
\hline d) & $\begin{array}{l}\text { Alcohol as an agent that } \\
\text { changes water }\end{array}$ & $5 \%$ & $4 \%$ \\
\hline e) & $\begin{array}{l}\text { Alcohol as a barrier or } \\
\text { insulator AND Alcohol as } \\
\text { freezing retardant }\end{array}$ & 0 & $11 \%$ \\
\hline f) & No agency & $50 \%$ & $26 \%$ \\
\hline
\end{tabular}

Table 6: Example of changes in agency in students' written explanations

\begin{tabular}{|c|c|c|}
\hline Student & Pre-lesson explanation & Post-lesson explanation \\
\hline 47 & $\begin{array}{l}\text { Alcohol works as a temperature } \\
\text { insulator for water (Agency: a). }\end{array}$ & $\begin{array}{l}\text { Well, what happens at the } \\
\text { molecular level is that the } \\
\text { solute prevents water } \\
\text { molecules from grouping } \\
\text { and ordering to get frozen } \\
\text { (Agency: a). }\end{array}$ \\
\hline 23 & $\begin{array}{l}\text { They act as anti-freezer } \\
\text { because the components in the } \\
\text { alcohol cause the temperature } \\
\text { of water to raise and thus it } \\
\text { does not freeze (Agency: b). }\end{array}$ & $\begin{array}{l}\text { Because the alcohol } \\
\text { particles don't let the } \\
\text { water particles to get } \\
\text { ordered and thus it } \\
\text { doesn't freeze (Agency: a). }\end{array}$ \\
\hline 18 & $\begin{array}{l}\text { Because when combining } \\
\text { alcohol with water, it causes } \\
\text { the alcohol to become a barrier } \\
\text { that prevents water from } \\
\text { freezing because it prevents } \\
\text { temperature from affecting the } \\
\text { water in the engine (Agency: a). }\end{array}$ & $\begin{array}{l}\text { Water doesn't freeze } \\
\text { because the alcohol } \\
\text { hinders water particles } \\
\text { from ordering fast and } \\
\text { thus it needs a larger } \\
\text { temperature change to } \\
\text { freeze (Agency: e). }\end{array}$ \\
\hline
\end{tabular}

ordering of water molecules. For student 23, the alcohol passed from being a source of energy to be a barrier for ordering, while student 18 initially thought of the alcohol as a barrier to freezing and then characterized alcohol as a retardant.

\section{Explanation built during the lesson}

One could expect students' post-lesson explanations to be influenced by the discourse and events that took place during the lesson. Thus, the explanation that the participating teacher built with her students was also characterized using a reasoning diagram in our analysis. This diagram is presented in figure 4 , together with a transcript of a moment during the lesson in which the teacher summarized the core idea she wanted the students to understand. In this explanation, we identified references to two entities (water and alcohol molecules) and to an activity (hindering) of one entity (alcohol molecules) that affected an activity (ordering) of the other entity (water molecules). In this case, there is no reference to any

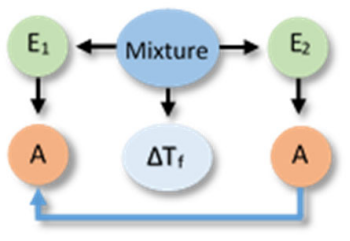

"If we think, for a substance to freeze it has to get ordered. If I am alone, happy, (points to figure representing pure water at the molecular level) and the temperature begins to decrease, the molecules will begin to order, right? If I have a solution and the temperature begins to decrease, like Laura said, it will take more for the water molecules to get ordered, right? The solute is interfering there. Then, they can get ordered, but it will take a longer time."

Fig. 4: Teacher's explanation and corresponding reasoning diagram. 
properties of the entities involved or to their specific spatio-temporal organization. In terms of agency, the alcohol is conceived as an entity that interferes with the ordering of water molecules, delaying freezing (alternative conception). Not surprisingly, this explanation shares many similarities with the ones generated by students after the lesson. In the following paragraphs, we analyse how this "convergence" was achieved by the teacher through different pedagogical interventions. We use excerpts from one of the lessons to illustrate the nature of the teacher's interventions observed in both classes.

As summarized in figure 1, the teacher guided the lesson using the same plan in both class sections. Thus, we present examples from only one of the lessons as they are representative of her interventions and actions in both cases. She began the lesson by directing students to analyse differences between water in the solid and liquid states at the molecular level. She presented a video that dynamically represented the freezing of water at the particulate level, and then posed the question: "What is the difference when we have solid water versus liquid water? What is the difference at the molecular level? Katie?" She directed the question to a specific student (pseudonym, Katie), but interacted with several students as she explored their thinking as shown in the following excerpt:

Teacher: What is the difference when we have solid water versus liquid water? What is the difference at the molecular level? Katie? Katie: That the solid ones are much closer

Teacher: Are we all in agreement with that? What happens if I put a bottle full with water in the freezer? What do you think?

\section{Student: It explodes}

Teacher: Why does it explode?

Students: (unintelligible responses)

Teacher: It is like a beer bottle which has a high percentage of water. If one freezes the bottle full with water, or the beer bottle, it bursts. Why does it burst?

Student: With the beer bottle or the water bottle, one has to make a sudden movement, like hitting the bottle for it to explode because if one just does it normally....

Teacher: Please, raise your hand to participate. Carlos?

Carlos: I think the gas explodes

Teacher: Louder, Carlos. Gas? If the water is normal? Yeah, beer has gas, but if it is tap water? Not carbonated.

Katie: The same, because the particles are like looser at the moment when they squish together

Teacher: What Katie says is what happens with all liquids. At the moment they freeze, their particles get closer together, except with water. Then, what is going to happen in the case of water? The water expands... You could do the experiment. If we make ice in the freezer and put water up to the rim, when we take it out, the ice surpasses the rim. Have you noticed it? And if you just fill half with water, then the ice fills the container. Thus, are the water molecules closer?

Students: No.

Teacher: No, right? In fact, the molecules expand. This is, they get farther apart not closer together
In this conversation, the teacher intended for the students to recognize that water expands (its molecules get farther apart) when freezing by asking them to think about what happens when a water bottle is put inside a freezer. In her interactions, the teacher elicits student reasoning (the bottle explodes), monitors student understanding (why does it explode?), redirects student thinking (what if we have pure water with no gas?), selects meanings (what Katie says is...) and uses these ideas to present a targeted explanation (molecules of water get farther apart when water freezes). By the end of this dialogue, the teacher has marked several meanings, such as the special properties of water upon freezing (expansion versus contraction) and the general change in the distribution of water molecules that occurs during the process. The targeted phenomenon (water expands upon freezing) is explained in terms of the spatial separation of molecular entities.

After this interaction, the teacher created another opportunity to explore students' ideas by posing the following question:

Teacher: In regards to molecular ordering, where do you think are molecules more ordered, when they are in the solid state or in the liquid state? Let's talk about water, when they are in the solid state or when they are in the liquid state? Raising your hand. Laura (pointing to a student).

In posing this question, the teacher seemed to want to direct her students' attention to an additional aspect of molecular organization (degree of ordering). Nevertheless, the interaction with students takes the conversation in a different direction:

\section{Laura: Solid \\ Teacher: ¿Why? \\ Student: Because they are tighter together}

Teacher: Are they tighter? In the solid state? Why? Why would they be squished together in the solid state? Marisa? Antonio?

Antonio: Because there is less energy

Teacher: Excellent! Less kinetic energy, right? Everybody knows it. That does not change in water. Just because molecules are farther apart, that does not change the fact that they have less kinetic energy. Then, let's see this (she projects an image from the video), what is the difference at the molecular level?

In this dialogue, students reverted back to the idea that molecules in the solid state are closer to each other than in the liquid state. When the teacher pressed for further explanation (why are they closer?), a student introduced a new idea based on the lesser amount of energy in the system. The teacher marked the idea by revoicing, shaping, and sharing it with the class, but actually did not pursue it. Instead, she presented a static molecular image of water in the liquid and solid states to redirect students' attention to molecular organization (ordering of water molecules):

Teacher: Pay attention to this, water molecules in the solid state. Internet images of ice crystals are different. When water freezes, it forms highly ordered structures. When the water molecules begin to order, they take more space. Look at the chaos in the 
liquid state, right? The order that we have in the solid state, do you see it? Right? I just wanted you to see this image. Water in the solid state has a highly ordered structure versus water in the liquid state

In this explanation, the teacher highlights the ordering activity of water molecules during the freezing process. To monitor students' understanding and recapitulate meanings, she then asked:

Teacher: Thus, what has to happen at the molecular level for a substance to freeze? Raising your hands, Jorge.

Jorge: It has to get ordered

Teacher: Molecules have to get ordered, right? Katie.

Katie: Mrs., and why it only happens in water?

Teacher: This happens to all substances

Student: No, but the fact that it expands

Teacher: Because of hydrogen bonding. But that we will discuss in another moment, because it does not have to do much with this. Because of hydrogen bonding, but it would require us to go into much detail. It has to do with the hydrogen bonds that water forms. Carlos?

Carlos: In that case, water would have to be a polar substance? Teacher: Yes. Let's go back to our image.

In this excerpt, we can see the teacher selecting the meanings she wanted to pursue and discarding others. She marked the idea of ordering of water molecules during the freezing process but a student questioned why water expands upon freezing. The teacher referred to a specific property of water molecules (hydrogen bonding) to justify the behavior, but indicated that going into that level of detail was unnecessary. Another student referred to polarity as specific property of water to justify the behavior, an idea that the teacher confirmed but chose not to pursue either. In general, the teacher emphasized the importance of one activity of water molecules (ordering) during her interactions with students, minimizing discussions related to specific properties of water that affected the phenomenon under consideration (water freezing).

In the next part of the lesson, the teacher asked students to consider the differences in the freezing behaviors of pure water and a solution of water with salt as illustrated in the following class excerpt:

Teacher: ... if we have pure water and need to freeze it, and if we have water with salt and we need to freeze it too, what needs to happen for them to freeze? In which case, the pure solvent or the solution will be harder for them to freeze? Why? The why is what matters most.

Student: I believe... in the solution

Teacher: It will be harder in the solution.

Student: because where we have the solute it would be harder for the particles to order, because the particles are different

Teacher: OK, what else? Someone agrees? Anyone thinks something different?
Student 1: I think the same thing. The solute is very important because of its different components, no? yes?

Teacher: You said you thought the same thing, but?

Student 1: ehh, what do you call it? Because it has other components besides pure water. Maybe because how the solute is composed, it may be harder to freeze it.

In this interaction, the teacher explored students' ideas without selecting or marking any of them. There were no attempts to monitor student understanding either. In general, students assumed that the alcohol had a property that would affect the freezing of water but without providing any details on what that property may be or about the mechanism through which the effect would occur. The teacher then just moved to provide an explanation:

Teacher: ... If we think, for a substance to freeze it has to get ordered. If I am alone, happy, (points to figure representing pure water at the molecular level) and the temperature begins to decrease, the molecules will begin to order, right? If I have a solution and the temperature begins to decrease, like Laura said, it will take more for the water molecules to get ordered, right? The solute is interfering there. Then, they can get ordered, but it will take a longer time

The teacher introduced the idea that the molecules of the solute (alcohol) interfered with the ordering of water molecules during freezing, causing the process to take a longer time. In the above excerpt, the teacher conflated the effect of the solute on the freezing point (depression of the freezing temperature) with a change in the time it would take for the mixture to freeze. Nevertheless, the analysis of the subsequent dialogue shows that she wanted students to recognize that the freezing temperature of the solution would be lower than that of the pure solvent:

Teacher: What needs to happen for the solution to freeze, if, let say, pure water freezes at zero Celsius? What should happen? Raúl?

Raúl: The freezing points will have to equalize.

Teacher: Louder!

Student: They need to equalize...

Teacher: Is the solution going to freeze at zero Celsius?

Students: No.

Teacher: At what temperature is the solution going to freeze? Katie?

Katie: I believe that lower

Teacher: OK. This is something we need to be careful about, because we need to lower the temperature. What will happen as we lower the temperature?

Student: It will freeze faster

Teacher: It freezes more, right? If I keep lowering the temperature, that favors ordering and the solution is going to freeze. 
In this excerpt, we can see that the conflation of ideas related to changes in freezing time versus changes in freezing temperature due to the presence of the solute was also present in students' ideas and was not resolved by the teacher. When a student implied that the solution would freeze faster at lower temperatures, the teacher shaped the meaning to indicate that lower temperatures would favor more order in the system. Then, she moved to discuss how the concentration of the solute would affect the freezing point as shown in this excerpt:

Teacher: And if I have a salt solution and I add twenty salt teaspoons and then other with fifty teaspoons, which one is going to freeze at a lower temperature?

Students: the one with more teaspoons

Teacher: Why?

Student: Because it has a larger amount of solute

Teacher: And? Then? It has a larger amount of solute? Based on what we said before, what does it need? At the molecular level, what needs to happen?

Student: that because the molecules get disordered, then like the salt needs to get to a lower point for all the molecules to get ordered

Teacher: That's it, OK? That's the full answer, remember.

Through this dialogue and the rest of the lesson, the teacher emphasized that the solute affected the ordering of water molecules, "delaying" the freezing process. She highlighted the idea that this effect did not depend on the nature of the solute but on its concentration, without providing an explanation for this behavior. She consistently referred to the activities of the solute (hindering) and the solvent (ordering) during freezing, but never discussed the actual molecular mechanism responsible for the effect.

\section{Discussion}

Our investigation revealed significant shifts in the types of explanations generated by participating students after a lesson on freezing point depression. Although a large percentage of students expressed the same type of reasoning in their pre- and post-lesson explanations, there was also a significant number of students who transitioned towards simple causal reasoning in which explanations of the phenomenon were based on the activities of one or more of the system's entities. These types of transitions occurred in both directions, from more simplistic forms of reasoning (i.e., descriptive and relational) to simple causal and from more sophisticated types of reasoning (e.g., emerging mechanistic) to simple causal. Other types of transitions between reasoning levels were observed in our study, but they were less common. The diversity of types of causal agency commonly invoked was also reduced between the pre- and post-lesson responses, favoring explanations in which one of the entities (the alcohol) acted as a barrier or retardant in the freezing process of the other entity (water).

Our analysis of teacher-student interactions during the observed lesson suggests that the teacher's mediation played a central role in the shift towards simple causal reasoning that was observed.
Through her interactions with students, the teacher built an explanation focused on one activity of the solute (hindering) acting on one activity of the solvent (ordering), without specific reference to the mechanism by which interactions between the two entities occurred. The teacher also deemphasized the effect that specific properties of the two components had on the phenomenon to be explained (freezing point depression). No references to spatiotemporal organization of the entities in the system were made either. Thus, it may not be surprising that many of the post-lesson explanations generated by the students aligned with the type of reasoning emphasized during the lesson. Even in those cases in which transition to a different type of reasoning was not observed, the content of the explanations included reasoning components introduced and discussed during the lesson.

In the two classes observed, the teacher used different pedagogical interventions to elicit students' ideas, select, mark, shape, and share meanings, and monitor student understanding (Mortimer \& Scott, 2002). Through these interventions, the teacher communicated what concepts and ideas were relevant in the construction of the explanation, and which ones were not appropriate or necessary for understanding the phenomenon. Although the teacher often acknowledged the different ideas expressed by her students, she did not pursue them as part of the classroom conversations and often reshaped them to fit her own narrative. From this perspective, the observed classroom talk could not be considered as exploratory or accountable talk (Wolf, Crosson and Resnick, 2006) as most of the key ideas were introduced, selected, or reshaped by the teacher.

The teacher engaged students in the construction of a rather simple causal explanation of freezing point depression. This explanation had elements of "centralized" causality in which the actions of a central, active entity (the alcohol in this case) are assumed to determine the behavior of more passive entities in a system (the water in our example) (Grotzer, 2003; Resnick, 1994; Talanquer, 2010). No references to the dynamic nature of the freezing and processes were made, and there was no consideration of how the presence of the solute affected the probability of these dynamic events. This outcome is consistent with studies about the characteristics of first-year prospective teachers' explanation of this topic (Çokadar, 2009).

Research has shown that orchestrating productive discourse in science classrooms is not easy and requires considerable teacher effort (Alozie et al. 2010). Teachers should have a solid grasp of the targeted concepts and ideas and strong pedagogical skills to move student thinking forward by asking questions, exploring ideas, and redirecting conversations (van Zee et al. 2001). Consistent with prior investigations on science teachers' practices (Harris et al. 2012), the teacher in our study was more skilled at eliciting students' ideas than at helping students develop them with proper scaffolding.

\section{Implications}

Our analysis highlights the central roles that a teacher's knowledge, intentions, and pedagogical interventions have on her students' expressed reasoning at the end of a lesson. Classroom talk allows 
students to recognize important ideas and reach collective understandings through interaction (Mercer, 2004; Jeong and Chi, 2007), but a teacher's mediation greatly influences the learning outcomes. In our case, the ways in which the teacher understood or decided to talk about freezing point depression in the two observed classes reshaped her students' expressed reasoning, advancing their ideas in some cases but also constraining their thinking in others. In particular, emerging mechanistic forms of explanation essentially disappeared as a result of the intervention and simple "centralized" causal ways of thinking became dominant.

The participating teacher in our study frequently elicited her students' ideas and sought to guide their thinking throu questioning. She engaged in several high-leverage teaching practices (Grossman et al., 2009), but her thinking and action seemed constrained by different factors. Her content knowledge and understanding of the phenomenon under consideration may have been limited, as attested by the centralized explanation that she built and the conflation of time and temperature effects on the phenomenon under discussion. It is also possible that her understanding of how to help students build meaning through dialogue may have been underdeveloped given her tendency to reshape her students' expressed thinking and to not pursue their ideas. Nevertheless, she was able to help many students advance in their reasoning.

It is unlikely that the teacher had reflected, or had given the opportunity to reflect in her professional training, about the different types of explanations that can be built about chemical phenomena (Talanquer, 2018) or about the different levels of reasoning at which such explanations can be built (Sevian and Talanquer, 2014). Teacher preparation and professional development programs rarely engage prospective or in-service teachers in the analysis of content knowledge from historical, philosophical, epistemological, and pedagogical perspectives to enrich their understanding of different ways of explaining and constructing explanations in the discipline (Freire, Talanquer and Amaral, 2019). The results of our study suggest that this type of engagement with the subject matter would help teachers approach the construction of explanations in the classroom in richer and more dialogic ways (Mortimer \& Scott, 2002).

Making teachers discuss and reflect on both the different types of reasoning that students often express and the quite sophisticated ways of thinking that they are capable of manifesting with proper scaffolding, could help teachers become more responsive to their students' ideas and use those ideas in more meaningful and productive ways in the construction of classroom explanations. Our work indicates that the successful implementation of high-leverage teaching practices may require the development of teachers' PCK on two critical areas: specific ways of reasoning in the discipline and student reasoning in the domain.

\section{Limitations}

Given the nature of our study, one should be cautious in making generalizations of our findings. We observed only one lesson taught by a single teacher in two different classrooms in a Chilean high school. The nature of the chemistry content that was taught in the observed lesson may have imposed constraints on the teachers' decisions and actions. Colligative properties are often explained using simple causal models in introductory chemistry courses, given the perceived complexities of dynamic explanations invoking competing processes with different probabilities of occurrence. Gijven her training and pedagogical content knowledge, it is possible that the observed teacher negotiated meanings in the classroom using a different approach when working with other topics. More observations of diverse teachers working on different topics and in diverse learning environments are needed to better understand the potentialities and challenges of teacher mediation in fostering student reasoning.

\section{Conflicts of interest}

There are no conflicts to declare.

\section{Acknowledgements}

This work was funded by the CONICYT PFCHA/DOCTORADO BECA DOCTORADO NACIONAL/2016 - 21161280 and by the research project FONDECYT 1160148 in Chile.

\section{References}

Alozie, N. M., Moje, E. B., \& Krajcik, J. S. (2010). An analysis of the supports and constraints for scientific discussion in high school project-based science. Sci. Educ., 94, 395-427.

Alvarado, C., Garritz, A., \& Mellado, V., (2015), Canonical pedagogical content knowledge by CoRes for teaching acid-base chemistry at high school. Chem. Educ. Res. Pract., 16(3), 603-618.

Aydeniz, M. and Dogan, A., (2016), Exploring pre-service science teachers' pedagogical capacity for formative assessment through analyses of student answers, Res. Sci. Technol. Educ., 34(2), 125141.

Becker, N., Noyes, K. and Cooper, M., (2016), Characterizing Students' Mechanistic Reasoning about London Dispersion Forces, J. Chem. Educ., 93(10), 1713-1724.

Bell, B. and Cowie, B., (2001), The characteristics of formative assessment in science education, Sci. Educ., 85(5), 536-553.

Çokadar, H., (2009), First year prospective teachers ' perceptions of molecular polarity and properties of solutions. Asian J. Chem., 21(1), 75-85.

Creswell, J. W., (2013) Qualitative inquiry and research design: choosing among five approaches, Qualitative Inquiry and Research Design. Thousand Oaks, CA: Sage.

Dawes, L,. (2004), Talk and learning in classroom science, Int. J. Sci. Educ., 26(6), 677-695.

Freire, M., Talanquer, V., \& Amaral, E., (2019), Conceptual profile of chemistry: a framework for enriching thinking and action in chemistry education. Int. J. Sci. Educ. 1-19.

Garriz, A., Nieto, E., Padilla, K., de María Reyes-Cárdenas, F., \& 
Velasco, R. T., (2008), Conocimiento didáctico del contenido en química. Lo que todo profesor debería poseer. Campo Abierto. Rev. Educ., 27(1), 153-177.

Grossman, P., Hammerness, K. and McDonald, M., (2009), Redefining teaching, re-imagining teacher education, Teach. Teach., 15(2), 273-289.

Grotzer, T., (2012), Learning Causality in a Complex World: Understandings of Consequence. Lamham, MD: R\&L Education.

Grotzer T. A., (2003), Learning to understand the forms of causality implicit in scientifically accepted explanations. Stud. Sci. Educ., 39(1), 74.

Harris, C., Phillips R., \& Penuel, W. (2012). Examining teachers' instructional moves aimed at developing students' ideas and questions in learner-centered science classrooms. J. Sci. Teach. Educ. 23(7): 769.

Izquierdo M. and Aliberas J., (2004), Pensar, actuar i parlar a la classe de ciències. Per un ensenyament de les ciències racional razonable, Cerdanyola, Spain: Servei Publicacions UAB.

Jeong, H. and Chi, M. T. H., (2007), Knowledge convergence and collaborative learning. Instr. Sci., 35(4), 287-315.

Levin, D., Hammer, D., \& Coffey, J. (2009). Novice teachers' attention to student thinking. J. Teach. Educ. 60(2), 142-154.

Maeyer, J. and Talanquer, V., (2010), The role of intuitive heuristics in students' thinking: Ranking chemical substances, Sci. Educ., 94(6), 963-984.

Magnusson, S., Krajcik, J. and Borko, H., (1999), Nature, Sources, and Development of Pedagogical Content Knowledge for Science Teaching. In Gess-Newsome, J. and Lederman, N. G. (Eds.), Examining pedagogical content knowledge: The construct and its implications for science education. Dordrecht, the Netherlands: Kluwer Academic Publishers, pp.95-132.

Maine, F. and Hofmann, R., (2016), Talking for meaning: The dialogic engagement of teachers and children in a small group reading context. Int. J. Educ. Res., 75, 45-56.

McDonald, M., Kazemi, E., Kelley-Petersen, M., Mikolasy, K., Thompson, J., Valencia, S. W., \& Windschitl, M., (2014), Practice makes practice: Learning to teach in teacher education. Peabody J. Educ., 89(4), 500-515.

McNeill, K. L. and Krajcik, J. S., (2012), Supporting grade 5-8 students in constructing explanations in science : the claim, evidence, and reasoning framework for talk and writing. New York, NY: Pearson Allyn \& Bacon.

Mercer, N., (2004), Sociocultural discourse analysis: analysing classroom talk as a social mode of thinking, J. Appl. Linguist., 1(2), 137-168.

Mercer, N. and Howe, C., (2012), Explaining the dialogic processes of teaching and learning: The value and potential of sociocultural theory, Learn. Cult. Soc. Inter., 1(1), 12-21.

Michaels, S., O' Connor, C. and Resnick, L. B., (2008), Deliberative Discourse Idealized and Realized: Accountable Talk in the Classroom and in Civic Life, Stud. Philos. Educ., 27, 283-297.

Michaels, S. and O'Connor, C., (2015), Conceptualizing Talk Moves as Tools: Professional Development Approaches for Academically Productive Discussions. In Resnick, L. B., Asterhan, C. S. C., and Clarke. S. N., (Eds.), Socializing Intelligence Through Academic Talk and Dialogue, Washington, DC: AERA, pp. 347-362.

Miles, M. and Huberman, A., (1994), Qualitative data analysis: an expanded sourcebook. 2nd ed. Thousand Oaks; CA: Sage.

Moreira, P., Marzabal, A. and Talanquer, V., (2019), Using a mechanistic framework to characterise chemistry students' reasoning in written explanations, Chem. Educ. Res. Pract.,20(1), 120-131.
Mortimer, E. and Scott, P., (2002), Atividade discursiva nas salas de aula de ciências: uma ferramenta sociocultural para analisar e planejar o ensino, Investigações em Ensino de Ciências, 7(3), 283306.

Resnick, M., (1994), Turtles, termites, and traffic jams : explorations in massively parallel microworlds. Cambridge, MA: MIT Press.

Rojas-Drummond, S., Torreblanca, O., Pedraza, H., Vélez, M., and Guzmán, K., (2013), Dialogic scaffolding: Enhancing learning and understanding in collaborative contexts. Learn. Cult. Soc. Inter. 2(1), 11-21.

Russ R. S., Coffey J. E., Hammer D., and Hutchison P., (2009), Making classroom assessment more accountable to scientific reasoning: A case for attending to mechanistic thinking. Sci. Educ., 93(5), 875-891.

Russ R. S., Scherr R. E., Hammer D., and Mikeska J., (2008), Recognizing mechanistic reasoning in student scientific inquiry: $A$ framework for discourse analysis developed from philosophy of science. Sci. Educ., 92(3), 499-525.

Russ, R. S., (2018), Characterizing teacher attention to student thinking: A role for epistemological messages. J. Res. Sci. Teach., 55(1), 94-120.

Sevian H. and Talanquer V., (2014), Rethinking chemistry: a learning progression on chemical thinking. Chem. Educ. Res. Pract., 15(1), 10-23.

Shulman, L., (1987), Knowledge and teaching: Foundations of the new reform, Harvard Educ. Rev., 57(1), 1-23.

Talanquer, V., (2004), Formación docente: ¿Qué conocimiento distingue a los buenos maestros de química?. Educ. Quim. 15(1), 60-66.

Talanquer, V., (2010), Exploring dominant types of explanations built by general chemistry students. Int. J. Sci. Educ, 32(18), 23932412.

Talanquer, V., (2014), Chemistry education: Ten heuristics to tame. J. Chem. Educ., 91(8), 1091-1097

Talanquer, V., (2018), Chemical rationales: another triplet for chemical thinking. Int. J. Sci. Educ., 40(15), 1874-1890.

Thompson, J., Windschitl, M. and Braaten, M., (2013), Developing a Theory of Ambitious Early-Career Teacher Practice. Am. Educ. Res. J., 50(3), 574-615.

van Es, E. A. and Sherin, M. G. (2002). Learning to notice: scaffolding new teachers' interpretations of classroom interactions. J. Tech. Teach. Educ., 10(4), 571-596.

van Zee, E. H., Iwasyk, M., Kurose, A., Simpson, D., and Wild, J. (2001). Student and teacher questioning during conversations about science. J. Res. Sci. Teach. 38, 159-190.

Windschitl, M., Thompson, J., Braaten, M., \& Stroupe, D., (2012), Proposing a core set of instructional practices and tools for teachers of science. Sci. Educ., 96(5), 878-903.

Wolf, M. K., Crosson, A. C. and Resnick, L. B., (2006), Accountable Talk in Reading Comprehension Instruction. CSE Technical Report 670, National Center for Research on Evaluation, Standards, and Student Testing (CRESST). Los Angeles, CA: University of California.

Zaidan, G. and Morton, C. (2014) Why does ice float in water? TED-Ed video retrieved from https://ed.ted.com/lessons/whydoes-ice-float-in-water-george-zaidan-and-charles-morton, April 2019. 